in vivo $34: 1975-1980(2020)$

doi:10.21873/invivo.11994

\title{
Prognostic Significance of Histological Subtype in Soft Tissue Sarcoma With Distant Metastasis
}

\author{
HIROYUKI TSUCHIE ${ }^{1}$, MAKOTO EMORI $^{2}$, NAOHISA MIYAKOSHI ${ }^{1}$, HIROYUKI NAGASAWA $^{1}$, \\ KYOJI OKADA ${ }^{3}$, YASUTAKA MURAHASHI ${ }^{2}$, EMI MIZUSHIMA $^{2}$, \\ JUNYA SHIMIZU ${ }^{2}$, TOSHIHIKO YAMASHITA ${ }^{2}$ and YOICHI SHIMADA ${ }^{1}$ \\ ${ }^{1}$ Department of Orthopedic Surgery, Akita University Graduate School of Medicine, Akita, Japan; \\ ${ }^{2}$ Department of Orthopedic Surgery, Sapporo Medical University School of Medicine, Sapporo, Japan; \\ ${ }^{3}$ Department of Physical Therapy, Akita University Graduate School of Health Sciences, Akita, Japan
}

\begin{abstract}
Background/Aim: Few studies have examined the prognostic significance of histological subtypes in patients with soft tissue sarcoma (STS) and distant metastasis, and we evaluated the relationship between the histological subtypes and clinical outcomes. Patients and Methods: This retrospective study evaluated the histological subtypes of 105 patients with STS and distant metastasis. The STS histological subtypes were compared based on the clinical information. Results: The Kaplan-Meier curves for overall survival revealed that myxoid liposarcoma had a significantly better prognosis compared to Malignant Peripheral Nerve Sheath Tumor (MPNST) $(p=0.0221)$. In the multivariate logistic regression analyses, the independent predictors of a poor prognosis were: i) large size, ii) advanced stage, and iii) non-surgical treatment for metastasis $(p<0.05)$. The presence or absence of lung metastasis was not significantly associated with prognosis ( $p=0.4452)$. Conclusion: Myxoid liposarcoma had a better prognosis compared to MPNST in STS patients with distant metastasis. The surgical removal of distant metastatic lesions may improve the patient's prognosis.
\end{abstract}

Soft tissue sarcoma (STS) is relatively rare, and mainly occurs in middle-aged or older individuals. Despite its low incidence, STS has various histological subtypes, such as liposarcoma and synovial sarcoma, which results in relatively

This article is freely accessible online.

Correspondence to: Hiroyuki Tsuchie, Department of Orthopedic Surgery, Akita University Graduate School of Medicine, 1-1-1 Hondo, Akita 010-8543, Japan. Tel: +81 188846148, Fax: +81 188362617,e-mail: tuchikiti@yahoo.co.jp

Key Words: Soft tissue sarcoma, prognosis, distant metastasis, malignant peripheral nerve sheath tumor. small populations of patients with different histological types. Radical resection with adequate margins is important for treating STS, regardless of the histological subtype, in order to prevent local recurrence. However, recent developments in surgical treatment, radiotherapy, and chemotherapy have improved patient outcomes (1), and various studies have identified factors associated with prognosis among STS patients (2-10). There is consensus that distant metastasis, which mainly involves the lungs, has a strong influence on prognosis. However, the small sample sizes for each subtype typically prevent studies from identifying a clear relationship between subtype and prognosis, despite the fact that several reports have examined the prognostic significance of the STS histological subtypes $(2-8,11,12)$. Moreover, only few studies have examined this topic among patients with STS and distant metastases. Therefore, the present study aimed to examine the association of clinical outcomes with the histological subtypes and distant metastasis sites in patients with STS and distant metastasis.

\section{Patients and Methods}

The study's retrospective protocol was approved by the Institutional Review Board for Clinical Research at Akita University (approval number: 2337), and informed consent was obtained from all patients.

Subjects. We retrospectively identified 118 patients with STS involving the extremities or trunk who also developed distant metastasis (excluding the lymph nodes) and were treated at our two hospitals between 1994 and 2018. The present study focused on histological subtypes of STS with $\geq 5$ cases, so we only included a total of 105 patients with STS and distant metastasis (65 male patients and 40 female patients, mean age $=63.1$ years, range $=10-90$ years $)$.

The eligible histological subtypes with $\geq 5$ cases were as follows: i) dedifferentiated liposarcoma, ii) pleomorphic liposarcoma, iii) myxoid liposarcoma, iv) myxofibrosarcoma, v) undifferentiated pleomorphic sarcoma (UPS), vi) synovial sarcoma, vii) malignant peripheral nerve sheath tumor (MPNST), and leiomyosarcoma. The patients' records were searched to collect information regarding i) age, ii) sex, iii) histological subtype, iv) anatomical location of the tumor, v) size, vi) previous 
in vivo $34: 1975-1980(2020)$

Table I. Comparison patient characteristics among the histological subtype of soft tissue sarcoma.

\begin{tabular}{|c|c|c|c|c|c|c|c|c|c|}
\hline & $\begin{array}{l}\text { Dedifferentiated } \\
\text { liposarcoma }\end{array}$ & $\begin{array}{l}\text { Pleomorphic } \\
\text { liposarcoma }\end{array}$ & $\begin{array}{c}\text { Myxoid } \\
\text { liposarcoma }\end{array}$ & MFS & UPS & $\begin{array}{l}\text { Synovial } \\
\text { sarcoma }\end{array}$ & MPNST & LMS & $p$-value \\
\hline Number & 13 & 5 & 10 & 11 & 31 & 11 & 18 & 6 & \\
\hline Age (years) & $73.2 \pm 9.7 \mathrm{a}$ & $54.4 \pm 7.0$ & $57.7 \pm 13.6$ & $76.2 \pm 13.5 \mathrm{a}$ & $67.5 \pm 12.9 \mathrm{a}$ & $43.6 \pm 20.9$ & $57.7 \pm 18.5$ & $62.7 \pm 20.0$ & $<0.0001$ \\
\hline \multicolumn{10}{|l|}{ Gender } \\
\hline \multicolumn{9}{|l|}{ Location } & 0.2581 \\
\hline Extremity/axial & $8 / 5$ & $4 / 1$ & $7 / 3$ & $7 / 4$ & $17 / 14$ & $9 / 2$ & $5 / 13$ & $6 / 0$ & 0.0287 \\
\hline Size $(\mathrm{mm})$ & $150 \pm 65 b$ & $56 \pm 21$ & $106 \pm 42$ & $81 \pm 53$ & $117 \pm 65$ & $82 \pm 27$ & $100 \pm 48$ & $96 \pm 89$ & 0.0366 \\
\hline \multicolumn{10}{|l|}{ Metastasis at diagnosis } \\
\hline \multicolumn{10}{|l|}{$\begin{array}{l}\text { Past inappropriate } \\
\text { excision }\end{array}$} \\
\hline Present/none & $0 / 13$ & $0 / 5$ & $1 / 9$ & $0 / 11$ & $1 / 30$ & $0 / 11$ & $1 / 17$ & $1 / 5$ & 0.5973 \\
\hline \multicolumn{10}{|l|}{ FNCLCC classification } \\
\hline Grade I/II/III & $0 / 0 / 13$ & $1 / 1 / 3$ & $2 / 6 / 2 c$ & $3 / 2 / 6$ & $1 / 10 / 20$ & $0 / 2 / 9$ & $0 / 7 / 11$ & $3 / 1 / 2 d$ & 0.0005 \\
\hline \multicolumn{5}{|l|}{ AJCC stage } & $0 / 10 / 14 / 7$ & $0 / 1 / 7 / 3$ & $0 / 7 / 6 / 5$ & $2 / 1 / 2 / 1$ & 0.0798 \\
\hline \multicolumn{10}{|l|}{ Lung metastasis } \\
\hline Present/none & $11 / 2$ & $5 / 0$ & $4 / 6$ & $10 / 1$ & $27 / 4$ & $9 / 2$ & $13 / 5$ & $5 / 1$ & 0.0519 \\
\hline $\begin{array}{l}\text { Follow-up period } \\
\text { (months) }\end{array}$ & $31.6 \pm 35.4$ & $26.8 \pm 30.2$ & $78.7 \pm 84.8$ & $61.0 \pm 62.3$ & $44.4 \pm 59.9$ & $40.0 \pm 27.6$ & $25.4 \pm 23.9$ & $27.2 \pm 30.7$ & 0.1912 \\
\hline $\begin{array}{l}\text { Time to the appearance } \\
\text { of distant metastasis } \\
\text { (months) }\end{array}$ & e $15.3 \pm 19.4$ & $18.6 \pm 29.6$ & $47.4 \pm 68.5$ & $24.0 \pm 26.9$ & $20.1 \pm 35.1$ & $13.3 \pm 12.4$ & $13.6 \pm 16.7$ & $19.2 \pm 27.5$ & 0.3015 \\
\hline AWD period (months) & $15.8 \pm 22.0$ & $26.5 \pm 35.8$ & $21.8 \pm 38.1$ & $28.8 \pm 34.5$ & $15.1 \pm 19.2$ & $23.5 \pm 23.5$ & $12.7 \pm 15.4$ & $8.0 \pm 4.5$ & 0.5533 \\
\hline \multicolumn{10}{|l|}{$\begin{array}{l}\text { Outcome at the last } \\
\text { follow-up }\end{array}$} \\
\hline NED/AWD/dead & $0 / 2 / 11$ & $1 / 0 / 4$ & $1 / 3 / 6$ & $1 / 1 / 9$ & $3 / 4 / 24$ & $1 / 1 / 9$ & $0 / 1 / 17$ & $0 / 3 / 3$ & 0.3427 \\
\hline
\end{tabular}

Values are expressed as number (\%) or mean \pm standard deviation. MFS: Myxofibrosarcoma; UPS: undifferentiated pleomorphic sarcoma; MPNST: malignant peripheral nerve sheath tumor; LMS: leiomyosarcoma; FNCLCC: French Federation of Cancer Center Sarcoma Group; AJCC: American Joint Committee on Cancer; NED: no evidence of disease; AWD: alive with disease. aSarcoma $v$. synovial sarcoma $(p<0.01)$, bDedifferentiated liposarcoma $v s$. pleomorphic liposarcoma $(p<0.05)$, ${ }^{\mathrm{c}}$ Myxoid liposarcoma $v s$. dedifferentiated liposarcoma $(p<0.01)$, ${ }^{\mathrm{d}}$ Leiomyosarcoma $v s$. dedifferentiated liposarcoma $(p<0.05)$.

inappropriate excision, vii) metastasis at diagnosis, viii) stage of the primary tumor, ix) treatments for the primary and metastatic tumors, $\mathrm{x}$ ) follow-up period, and xi) outcomes. The stage of the primary tumor was determined according to the $7^{\text {th }}$ edition of the American Joint Committee on Cancer (AJCC) staging system (13). The specimens were also classified using the French Federation of Cancer Center Sarcoma Group (FNCLCC) system, which considers the i) mitotic index, ii) necrosis extension, and iii) histological differentiation (14). We obtained some information regarding the type of local therapy and surgical margins (Enneking criteria) for patients who underwent surgery. In the absence of any events, patients were censored at the last follow-up. We calculated the overall survival (OS) interval from the date of diagnosis to the date of death or the last follow-up. Outcomes and clinical characteristics were compared according to the patients' histological subtypes.

Statistical analysis. Values are reported as a number (\%) or mean \pm standard deviation. Inter-group comparisons were performed using analysis of variance, the $\chi^{2}$ test, or the Scheffé test for multiple comparisons among the 8 groups. Overall survival was compared using the Kaplan-Meier methods and long-rank test. A Cox proportional hazards model was used to identify the factors that were associated with OS. Differences were considered statistically significant at $p$-Values of $<0.05$.

\section{Results}

The mean follow-up period for all patients was $42.3 \pm 51.7$ months (range $=2-284$ months). The histological diagnoses were: i) dedifferentiated liposarcoma in 13 cases $(12.4 \%)$, ii) pleomorphic liposarcoma in 5 cases $(4.8 \%)$, iii) myxoid liposarcoma in 10 cases $(9.5 \%)$, iv) myxofibrosarcoma in 11 cases $(10.5 \%)$, v) UPS in 31 cases $(29.5 \%)$, vi) synovial sarcoma in 11 cases $(10.5 \%)$, vii) MPNST in 18 cases $(17.1 \%)$, and viii) leiomyosarcoma in 6 cases $(5.7 \%)$. The sites of the primary lesions were the extremities in 63 patients $(60 \%)$ and axial sites in 42 patients $(40 \%)$. The mean tumor size for all patients was $105.4 \pm 61.8 \mathrm{~mm}$ (range $=15-370 \mathrm{~mm}$ ). Previous inappropriate excision had been performed in 4 patients. The FNCLCC classifications were: i) Grade I for 10 patients, ii) Grade II for 29 patients, and iii) Grade III for 66 patients. According to the AJCC staging system, the disease stages were: i) IA for 1 patient, ii) stage IB for 7 patients, iii) 
Tsuchie et al: Sarcoma With Distant Metastasis

Table II. Comparing treatment methods among the histological subtypes of soft tissue sarcomas.

\begin{tabular}{|c|c|c|c|c|c|c|c|c|c|}
\hline & $\begin{array}{l}\text { Dedifferentiated } \\
\text { liposarcoma }\end{array}$ & $\begin{array}{l}\text { Pleomorphic } \\
\text { liposarcoma }\end{array}$ & $\begin{array}{c}\text { Myxoid } \\
\text { liposarcoma }\end{array}$ & MFS & UPS & $\begin{array}{l}\text { Synovial } \\
\text { sarcoma }\end{array}$ & MPNST & LMS & $p$-value \\
\hline Number & 13 & 5 & 10 & 11 & 31 & 11 & 18 & 6 & \\
\hline \multicolumn{10}{|l|}{$\begin{array}{l}\text { Surgical treatment } \\
\text { for primary tumor }\end{array}$} \\
\hline Present/none & $10 / 3$ & $4 / 1$ & $8 / 2$ & $8 / 3$ & $23 / 8$ & $10 / 1$ & $13 / 5$ & $4 / 2$ & 0.9579 \\
\hline \multicolumn{10}{|l|}{ Surgical margin } \\
\hline Adequate/inadequate & $4 / 6$ & $4 / 0$ & $6 / 2$ & $5 / 3$ & $16 / 7$ & $7 / 3$ & $9 / 4$ & $4 / 0$ & 0.3514 \\
\hline \multicolumn{10}{|c|}{ Radiation for primary tumor } \\
\hline Present/none & $1 / 12$ & $2 / 3$ & $0 / 10$ & $4 / 7$ & $6 / 25$ & $2 / 9$ & $4 / 14$ & $2 / 4$ & 0.3716 \\
\hline \multicolumn{10}{|l|}{ Chemotherapy } \\
\hline Present/none & $1 / 12$ & $3 / 2$ & $7 / 3$ & $4 / 7$ & $12 / 19$ & $8 / 3$ & $4 / 14$ & $4 / 2$ & 0.0076 \\
\hline \multicolumn{10}{|l|}{$\begin{array}{l}\text { Surgical treatment } \\
\text { for metastasis }\end{array}$} \\
\hline Present/none & $3 / 10$ & $1 / 4$ & $4 / 6$ & $5 / 6$ & $7 / 24$ & $3 / 8$ & $1 / 17$ & $1 / 5$ & 0.3412 \\
\hline \multicolumn{10}{|c|}{ Radiotherapy for metastasis } \\
\hline Present/none & $0 / 13$ & $0 / 5$ & $2 / 8$ & $0 / 11$ & $4 / 27$ & $0 / 11$ & $8 / 10$ & $1 / 5$ & 0.2847 \\
\hline \multicolumn{10}{|l|}{ Local recurrence } \\
\hline Present/none & $6 / 4$ & $0 / 4$ & $2 / 6$ & $3 / 5$ & $7 / 16$ & $2 / 8$ & $4 / 9$ & $1 / 3$ & 0.4687 \\
\hline
\end{tabular}

Values are expressed as number (\%) or means \pm standard deviations. MFS: Myxofibrosarcoma; UPS: undifferentiated pleomorphic sarcoma; MPNST: malignant peripheral nerve sheath tumor; LMS: leiomyosarcoma.

Table III. The p-Value results from the Kaplan-Meier curve comparisons among the histological subtypes of soft tissue sarcoma.

\begin{tabular}{lcccccrr}
\hline & $\begin{array}{c}\text { Pleomorphic } \\
\text { liposarcoma }\end{array}$ & $\begin{array}{c}\text { Myxoid } \\
\text { liposarcoma }\end{array}$ & MFS & UPS & $\begin{array}{c}\text { Synovial } \\
\text { sarcoma }\end{array}$ & MPNST & LMS \\
\hline Dedifferentiated liposarcoma $(p$-Value) & 0.9194 & 0.0911 & 0.3756 & 0.2909 & 0.6368 & 0.4820 & 0.5750 \\
Pleomorphic liposarcoma $(p$-Value) & - & 0.2998 & 0.2533 & 0.5046 & 0.6161 & 0.7670 & 0.4167 \\
Myxoid liposarcoma ( $p$-Value) & - & - & 0.3440 & 0.2377 & 0.2131 & 0.0221 & 0.5549 \\
MFS ( $p$-Value) & - & - & - & 0.7347 & 0.6761 & 0.0512 & 0.7741 \\
UPS $(p$-Value) & - & - & - & - & 0.9532 & 0.0989 & 0.8932 \\
Synovial sarcoma $(p$-Value) & - & - & - & - & - & 0.1179 & 0.8921 \\
MPNST $(p$-Value) & - & - & - & - & - & - & 0.3829 \\
\hline
\end{tabular}

MFS: Myxofibrosarcoma; UPS: undifferentiated pleomorphic sarcoma; MPNST: malignant peripheral nerve sheath tumor; LMS: leiomyosarcoma.

stage IIA for 4 patients, iv) stage II B for 23 patients, v) stage III for 47 patients, and vi)stage IV for 23 patients, with metastasis present at the diagnosis for 23 patients $(21.9 \%)$. Eighty-four patients $(80 \%)$ developed pulmonary metastases, and the sites of extra-pulmonary metastases were the bones in 19 patients, axial soft tissue in 12 patients, the brain in 6 patients, the mediastinum in 6 patients, extremity soft tissue in 5 patients, intraperitoneal in 5 patients, the liver in 4 patients, retroperitoneal in 4 patients, and the colon in 1 patient. The mean period until the appearance of distant metastasis for all patients was 20.6 \pm 33.1 months (range $=0$ 232 months) (Table I). Surgery for the primary tumor was performed for 80 patients $(76.2 \%)$, and adequate tumor-free margins were achieved for 55 patients $(68.8 \%)$. Radiotherapy was performed for 21 patients $(20 \%)$, which included heavy particle irradiation for 1 patient and radiotherapy plus surgery for 10 patients $(47.6 \%)$. Chemotherapy was administered to 43 patients $(40.1 \%)$, which involved doxorubicin, ifosfamide, dacarbazine, gemcitabine, cisplatin, etoposide, eribulin, trabectedin, and pazopanib. Surgical treatment was performed for the metastasis in 25 patients $(23.8 \%)$, and radiotherapy was performed for the metastasis in 15 patients $(14.3 \%)$. Twenty-five patients (23.8\%) developed local recurrence. The patient outcomes were no evidence of disease in 7 patients, alive with disease in 15 patients, and 83 patients who died because of their original disease. No patient died because of complications during the perioperative period. The mean period of survival with disease was $17.9 \pm 23.9$ months (range $=1-120$ months) (Table II).

Patients with synovial sarcoma were significantly younger compared to those with dedifferentiated liposarcoma, pleomorphic liposarcoma, or UPS. Dedifferentiated liposarcoma 


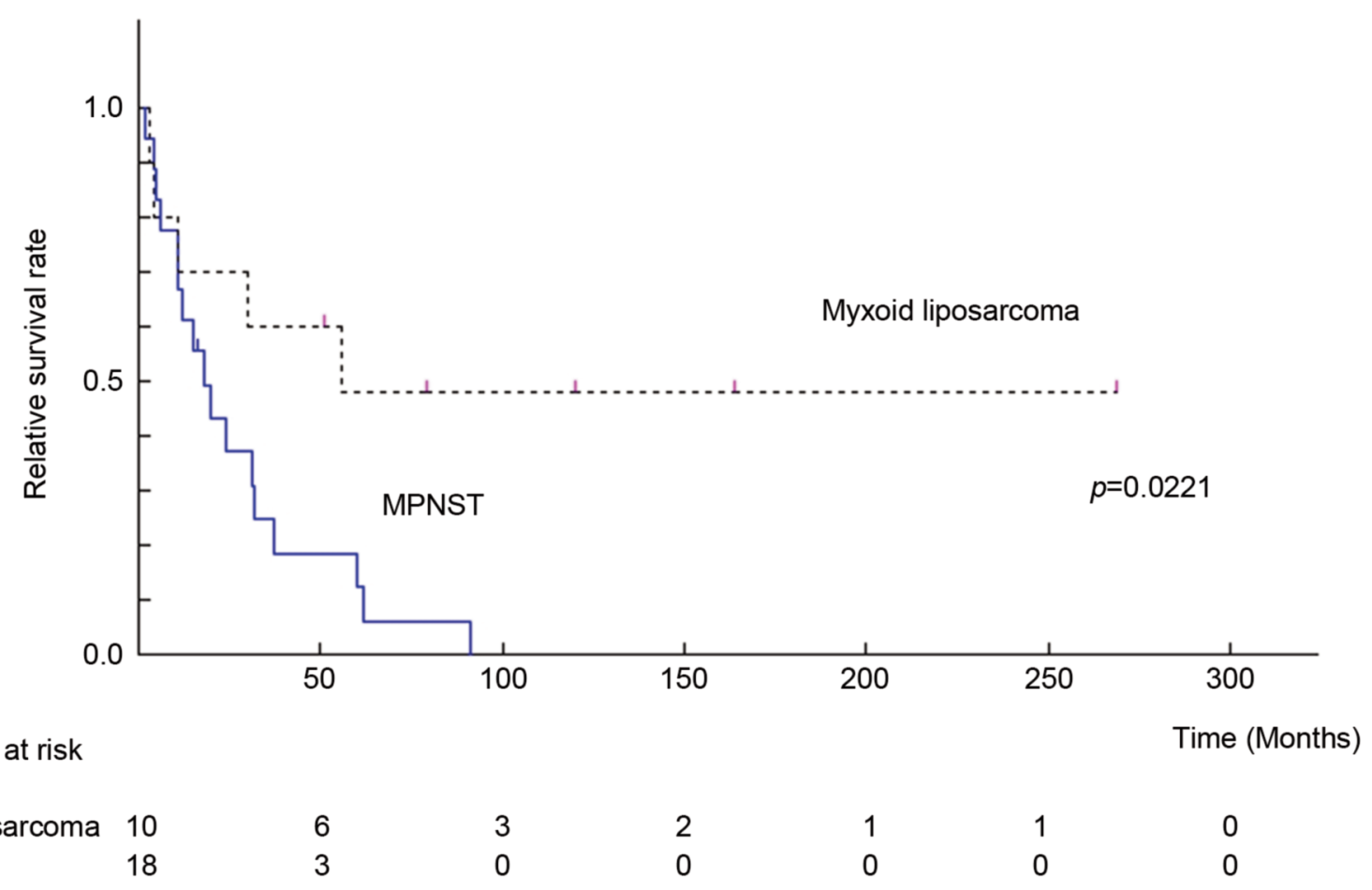

Figure 1. Kaplan-Meier overall survival (OS) curves. Myxoid liposarcoma shows higher OS compared to malignant peripheral nerve sheath tumor (MPNST) $(p=0.0221)$.

was significantly larger compared to pleomorphic liposarcoma. Dedifferentiated liposarcoma was significantly more malignant compared to myxoid liposarcoma or leiomyosarcoma, based on histological findings (Table I). The Kaplan-Meier overall survival curves revealed that myxoid liposarcoma had a significantly better prognosis compared to MPNST ( $p=0.0221)$ (Table III and Figure 1). The univariate and multivariate logistic regression analyses revealed that the prognosis of patients with STS and distant metastasis was associated with i) tumor size, ii) AJCC stage, and iii) surgical treatment for metastasis (all $p<0.05$ ) (Table IV).

\section{Discussion}

Patients with STS and distant metastasis are difficult to cure, regardless of the histological subtype, and have a poor prognosis. However, there is variation in the rate of tumor growth, the number of tumors, the site of development, and the period of survival with disease. To the best of our knowledge, no studies have examined the prognostic differences between the histological subtypes of STS in patients with distant metastasis. Our results revealed that MPNST had a poor prognosis than myxoid liposarcoma in this setting. Several reports have described variable differences in the prognosis between the histological subtypes, regardless of the presence or absence of distant metastasis. For example, some reports have described no difference in prognosis, while other reports have indicated that a relatively poor prognosis is associated with rhabdomyosarcoma, epithelioid sarcoma, clear cell sarcoma, MPNST, leiomyosarcoma, and malignant fibrous histiocytoma, as well as in dedifferentiated liposarcoma $(2,3$, $6-8,11,12)$. Callegaro et al. have also reported an overall survival nomogram that can be used to predict the patient's prognosis, based on age, tumor size, histological grade, and histological subtype (2). In that nomogram, vascular sarcoma was associated with the poorest prognosis, while myxoid liposarcoma was associated with the best prognosis. Moreover, MPNST reportedly has a poor prognosis (8) and myxoid liposarcoma has a good prognosis $(11,12)$, with the outcomes also potentially being affected by the occurrence of distant metastasis. In this context, chemotherapy and radiotherapy are thought to have an elevated influence on the prognosis of patients with distant metastasis. For example, myxoid liposarcoma is more responsive to radiotherapy and chemotherapy compared to other soft tissue sarcoma types (15-18), while MPNST does not respond to chemotherapy, and radiation-induced MPNST is associated with poor prognosis $(19,20)$. These distinct behaviors of the STS subtypes may differentially affect their outcomes after the appearance of distant metastasis. 
Tsuchie et al: Sarcoma With Distant Metastasis

Table IV. Univariate and multivariate analyses of potential prognostic factors.

\begin{tabular}{|c|c|c|c|c|c|c|}
\hline & \multicolumn{3}{|c|}{ Univariable } & \multicolumn{3}{|c|}{ Multivariable } \\
\hline & OR & $95 \% \mathrm{CI}$ & $p$-Value & OR & $95 \% \mathrm{CI}$ & $p$-Value \\
\hline Age & 1.010 & $0.996-1.024$ & 0.1636 & & & \\
\hline Female sex & 1.018 & $0.647-1.603$ & 0.9372 & & & \\
\hline Axial location & 1.218 & $0.779-1.906$ & 0.3878 & & & \\
\hline Size & 1.004 & $1.000-1.008$ & 0.0311 & 1.004 & $1.000-1.008$ & 0.0354 \\
\hline Past inappropriate excision & 0.527 & $0.165-1.684$ & 0.2799 & & & \\
\hline FNCLCC classification & 1.434 & $1.014-2.027$ & 0.0415 & 0.887 & $0.556-1.416$ & 0.6155 \\
\hline AJCC stage & 1.963 & $1.446-2.665$ & $<0.0001$ & 2.146 & $1.367-3.369$ & 0.0009 \\
\hline Lung metastasis & 1.233 & $0.720-2.112$ & 0.4452 & & & \\
\hline Surgical treatment for primary tumor & 0.297 & $0.182-0.484$ & $<0.0001$ & 0.774 & $0.391-1.534$ & 0.4634 \\
\hline Radiation for primary tumor & 1.762 & $1.045-2.972$ & 0.0336 & 1.744 & $0.974-3.123$ & 0.0614 \\
\hline Chemotherapy & 0.539 & $0.340-0.855$ & 0.0086 & 0.723 & $0.438-1.192$ & 0.2036 \\
\hline Surgical treatment for metastasis & 0.383 & $0.214-0.685$ & 0.0012 & 0.463 & $0.242-0.885$ & 0.0199 \\
\hline Radiation for metastasis & 0.967 & $0.523-1.788$ & 0.9142 & & & \\
\hline Dedifferentiated liposarcoma & 1.361 & $0.719-2.577$ & 0.3463 & & & \\
\hline Pleomorphic liposarcoma & 1.425 & $0.518-3.917$ & 0.4927 & & & \\
\hline Myxoid liposarcoma & 0.426 & $0.171-1.060$ & 0.0677 & & & \\
\hline Myxofibrosarcoma & 0.798 & $0.398-1.601$ & 0.5258 & & & \\
\hline Undifferentiated pleomorphic sarcoma & 0.912 & $0.558-1.492$ & 0.7145 & & & \\
\hline Synovial sarcoma & 0.935 & $0.466-1.877$ & 0.8506 & & & \\
\hline Malignant peripheral nerve sheath tumor & 1.779 & $1.033-3.061$ & 0.0376 & 1.168 & $0.649-2.101$ & 0.6049 \\
\hline Leiomyosarcoma & 0.864 & $0.272-2.747$ & 0.8044 & & & \\
\hline
\end{tabular}

OR: Odds ratio; 95\%CI: 95\% confidence interval; FNCLCC: French Federation of Cancer Center Sarcoma Group; AJCC: American Joint Committee on Cancer.

Although age, histological grade, stage, tumor diameter, and resection margins are reportedly associated with a poor prognosis for STS, few reports have evaluated factors influencing the prognosis of patients with STS and distant metastasis $(9,21-23)$. Some of these studies have indicated that surgical resection of the distant metastatic lesions can improve the prognosis, similar to what we observed. Thus, aggressive surgical treatment may be preferable if the distant metastatic lesions are considered resectable. The distant metastases from STS generally occur in the lungs (70-80\% of these patients) $(9,23-25)$, as in our cohort. However, the presence or absence of lung metastasis did not affect the prognosis, and Billingsley et al. have also reported no difference in prognosis between lung metastasis and other distant metastases (9).

The present study is limited by the small sample of patients, especially when considering each histological subtype, and only $<10$ cases of pleomorphic liposarcoma and leiomyosarcoma identified. Furthermore, various factors, including the treatment selection, might have biased our findings, as some patients received chemotherapy and/or radiotherapy. Therefore, further detailed studies are needed to evaluate a larger number of STS patients with distant metastasis.

In conclusion, the present study evaluated the clinical characteristics and outcome of patients with STS and distant metastasis, which revealed some differences regarding their prognosis according to histological subtype. For example, myxoid liposarcoma had a better prognosis compared to MPNST in this setting. While the surgical removal of distant metastasis may help improve the patient's prognosis, the location of the distant metastasis did not affect the prognosis.

\section{Conflicts of Interest}

The Authors report no conflicts of interest.

\section{Authors' Contributions}

All Authors were involved in the planning and revising of this research. TH, NH, EM, MY, ME, and SJ collected the clinical data. $\mathrm{TH}$ analyzed the raw data and wrote this dissertation. MN, OK, YY, and SY reviewed this manuscript.

\section{References}

1 Janssen S, Bolm L, Käsmann L, Bartscht T, Rades D: Palliative radiation therapy for spinal cord compression from metastatic soft tissue sarcoma. In Vivo 30(4): 529-531, 2016. PMID: 27381619.

2 Callegaro D, Miceli R, Bonvalot S, Ferguson P, Strauss DC, Levy A, Griffin A, Hayes AJ, Stacchiotti S, Pechoux CL, Smith 
MJ, Fiore M, Dei Tos AP, Smith HG, Mariani L, Wunder JS, Pollock RE, Casali PG and Gronchi A: Development and external validation of two nomograms to predict overall survival and occurrence of distant metastases in adults after surgical resection of localised soft-tissue sarcomas of the extremities: a retrospective analysis. Lancet Oncol 17(5): 671-680, 2016. PMID: 27068860. DOI: 10.1016/S1470-2045(16)00010-3

3 Smith HG, Memos N, Thomas JM, Smith MJ, Strauss DC and Hayes AJ: Patterns of disease relapse in primary extremity softtissue sarcoma. Br J Surg 103(11): 1487-1496, 2016. PMID: 27503444. DOI: $10.1002 /$ bjs. 10227

4 Italiano A, Le Cesne A, Mendiboure J, Blay JY, PipernoNeumann S, Chevreau C, Delcambre C, Penel N, Terrier P, Ranchere-Vince D, Lae M, Le Guellec S, Michels JJ, Robin YM, Bellera $\mathrm{C}$ and Bonvalot S: Prognostic factors and impact of adjuvant treatments on local and metastatic relapse of soft-tissue sarcoma patients in the competing risks setting. Cancer 120(21): 3361-3369, 2014. PMID: 25042799. DOI: 10.1002/cncr.28885

5 Gronchi A, Lo Vullo S, Colombo C, Collini P, Stacchiotti S, Mariani L, Fiore M and Casali PG: Extremity soft tissue sarcoma in a series of patients treated at a single institution: local control directly impacts survival. Ann Surg 251(3): 506-511, 2010. PMID: 20130465. DOI: 10.1097/SLA.0b013e3181cf87fa

6 Gutierrez JC, Perez EA, Franceschi D, Moffat FL Jr, Livingstone AS and Koniaris LG: Outcomes for soft-tissue sarcoma in 8249 cases from a large state cancer registry. J Surg Res 141(1): 105114, 2007. PMID: 17512548. DOI: 10.1016/j.jss.2007.02.026

7 Zagars GK, Ballo MT, Pisters PW, Pollock RE, Patel SR, Benjamin RS and Evans HL: Prognostic factors for patients with localized soft-tissue sarcoma treated with conservation surgery and radiation therapy: an analysis of 1225 patients. Cancer 97(10): 2530-243, 2003. PMID: 12733153. DOI: 10.1002/cncr.11365

8 Pisters PW, Leung DH, Woodruff J, Shi W and Brennan MF: Analysis of prognostic factors in 1,041 patients with localized soft tissue sarcomas of the extremities. J Clin Oncol 14(5): 1679-1689, 1996. PMID: 8622088. DOI: 10.1200/JCO.1996.14.5.1679

9 Billingsley KG, Lewis JJ, Leung DH, Casper ES, Woodruff JM and Brennan MF: Multifactorial analysis of the survival of patients with distant metastasis arising from primary extremity sarcoma. Cancer 85(2): 389-395, 1999. PMID: 10023707.

10 Tsuchie H, Kaya M, Nagasawa H, Emori M, Murahashi Y, Mizushima E, Miyakoshi N, Yamashita T and Shimada Y: Distant metastasis in patients with myxofibrosarcoma. Ups J Med Sci 122(3): 190-193, 2017. PMID: 28814152. DOI: 10.1080/03009734.2017.1356404

11 Greto D, Saieva C, Loi M, Terziani F, Visani L, Garlatti P, Lo Russo M, Muntoni C, Becherini C, Topulli J, Campanacci D, Beltrami G, Scoccianti G, Muratori F, Bonomo P, Desideri I, Francolini $G$ and Livi L: Influence of age and subtype in outcome of operable liposarcoma. Radiol Med 124(4): 290-300, 2019. PMID: 30421387. DOI: 10.1007/s11547-018-0958-4

12 Knebel C, Lenze U, Pohlig F, Lenze F, Harrasser N, Suren C, Breitenbach J, Rechl H, von Eisenhart-Rothe R and Mühlhofer HML: Prognostic factors and outcome of Liposarcoma patients: a retrospective evaluation over 15 years. BMC Cancer 17(1): 410, 2017. PMID: 28606068. DOI: 10.1186/s12885-017-3398-y

13 Edge SB and Compton CC (eds): AJCC Cancer Staging Handbook, $7^{\text {th }}$ ed. New York: Springer, 2010.

14 Coindre JM, Terrier P, Bui NB, Bonichon F, Collin F, Le Doussal V, Mandard AM, Vilain MO, Jacquemier J, Duplay H, Sastre X,
Barlier C, Henry-Amar M, Macé-Lesech J and Contesso G: Prognostic factors in adult patients with locally controlled soft tissue sarcoma. A study of 546 patients from the French Federation of Cancer Centers Sarcoma Group. J Clin Oncol 14(3): 869-877, 1996. PMID: 8622035. DOI: 10.1200/JCO.1996.14.3.869

15 Chowdhry V, Goldberg S, DeLaney TF, Cote GM, Chebib I, Kim J, Lozano-Calderón SA and De Amorim Bernstein K: Myxoid liposarcoma: Treatment outcomes from chemotherapy and radiation therapy. Sarcoma 2018: 8029157, 2018. PMID: 30515050. DOI: $10.1155 / 2018 / 8029157$

16 Salduz A, Alpan B, Valiyev N, Özmen E, İribaş A, Ağaoğlu F, Bayram A, Bilgiç B and Özger H: Neoadjuvant radiotherapy for myxoid liposarcomas: Oncologic outcomes and histopathologic correlations. Acta Orthop Traumatol Turc 51(5): 355-361, 2017. PMID: 28869066. DOI: 10.1016/j.aott.2017.03.009

17 Katz D, Boonsirikamchai P, Choi H, Lazar AJ, Wang WL, Xiao L, Park MS, Ravi V, Benjamin RS and Araujo DM: Efficacy of first-line doxorubicin and ifosfamide in myxoid liposarcoma. Clin Sarcoma Res 2(1): 2, 2012. PMID: 22587772. DOI: 10.1186/2045-3329-2-2

18 Peterson JJ, Kransdorf MJ, Bancroft LW and O'Connor MI: Malignant fatty tumors: classification, clinical course, imaging appearance and treatment. Skeletal Radiol 32(9): 493-503, 2003. PMID: 12802520 . DOI: 10.1007/s00256-003-0647-8

19 Yamanaka R and Hayano A: Radiation-induced malignant peripheral nerve sheath tumors: A systematic review. World Neurosurg 105: 961-970.e8, 2017. PMID: 28602926. DOI: 10.1016/j.wneu.2017.06.010

20 Kroep JR, Ouali M, Gelderblom H, Le Cesne A, Dekker TJ, Van Glabbeke M, Hogendoorn PC and Hohenberger P: First-line chemotherapy for malignant peripheral nerve sheath tumor (MPNST) versus other histological soft tissue sarcoma subtypes and as a prognostic factor for MPNST: an EORTC soft tissue and bone sarcoma group study. Ann Oncol 22(1): 207-214, 2011. PMID: 20656792. DOI: 10.1093/annonc/mdq338

21 Krishnan CK, Kim HS, Park JW and Han I: Outcome after surgery for extremity soft tissue sarcoma in patients presenting with metastasis at diagnosis. Am J Clin Oncol 41(7): 681-686, 2018. PMID: 27819879. DOI: 10.1097/COC.0000000000000346

22 Nakamura T, Katagiri H, Shido Y, Hamada S, Yamada K, Nagano A, Yamada S, Tsukushi S, Ishimura D, Matsumine A, Sudo A and Nishida Y: Analysis of factors for predicting survival in soft-tissue sarcoma with metastatic disease at initial presentation. Anticancer Res 37(6): 3137-3141, 2017. PMID: 28551655. DOI: 10.21873 /anticanres.11671

23 Nakamura T, Matsumine A, Matsubara T, Asamuma K, Niimi R, Uchida A and Sudo A: Retrospective analysis of metastatic sarcoma patients. Oncol Lett 2(2): 315-318, 2011. PMID: 22866083. DOI: $10.3892 / \mathrm{ol} .2011 .238$

24 Kane JM, Finley JW, Driscoll D, Kraybill WG and Gibbs JF: The treatment and outcome of patients with soft tissue sarcomas and synchronous metastases. Sarcoma 6(2): 69-73, 2002. PMID: 18521331. DOI: $10.1080 / 1357714021000022168$

25 Vezeridis MP, Moore R and Karakousis CP: Metastatic patterns in soft-tissue sarcomas. Arch Surg 118(8): 915-918, 1983. PMID: 6307217. DOI: 10.1001/archsurg.1983.01390080023007

Received March 18, 2020

Revised April 6, 2020

Accepted April 8, 2020 